
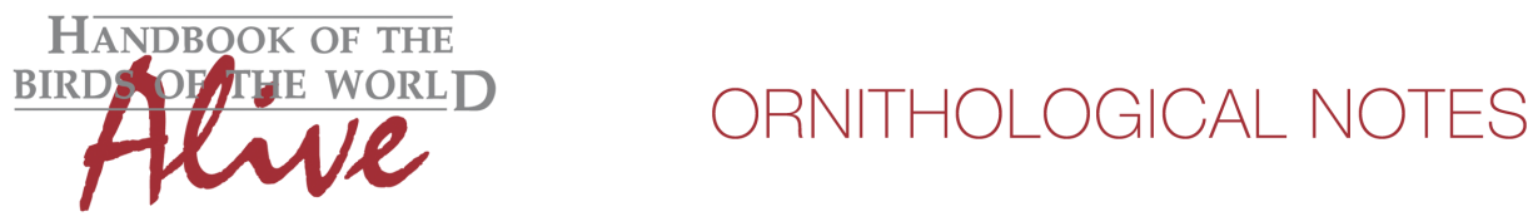

\title{
Notes on the vocalizations of Alpine Accentor (Prunella collaris)
}

Peter Boesman

In the following we briefly analyze and compare voice of the different races of Alpine Accentor (Prunella collaris). We also try to quantify the extent of any vocal differences using the criteria proposed by Tobias et al. (2010), as a support for taxonomic review. We have made use of sound recordings available on-line from Xeno Canto (XC).

Our main interest is to compare race erythropygia with other races, as the former was shown to be distinctive in a genetic analysis (Drovetski et al. 2013).

Surprisingly, there are very few recordings available of any race, and we have located only a single recording of erythropygia from Japan (which is rather at the extreme side of the geographical distribution of this race).

In this recording, song consists mainly of two note types: Short downslurred melodious notes (note type $A$ ) and a more trilled oscillating note (note type B).

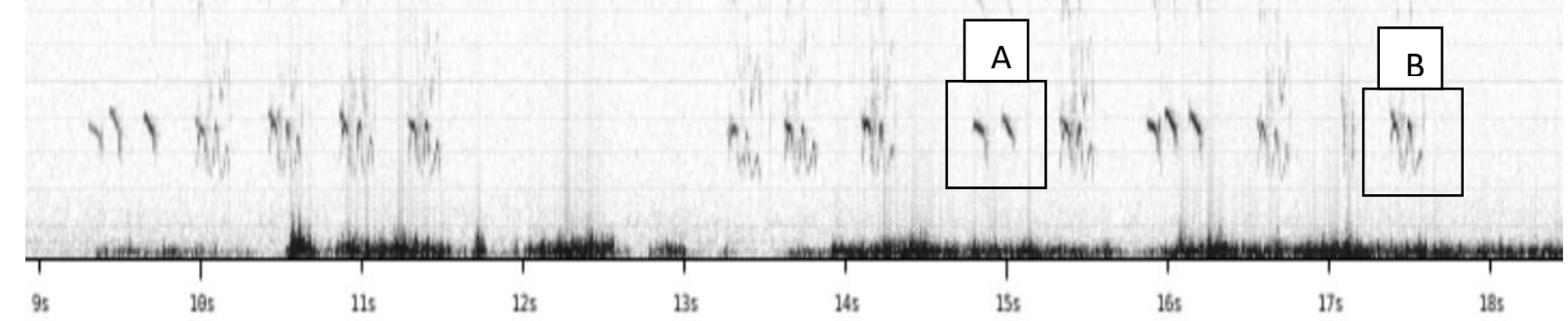

We have therefore looked if we can find back these note types in other races. an overview with examples from west to east:

France

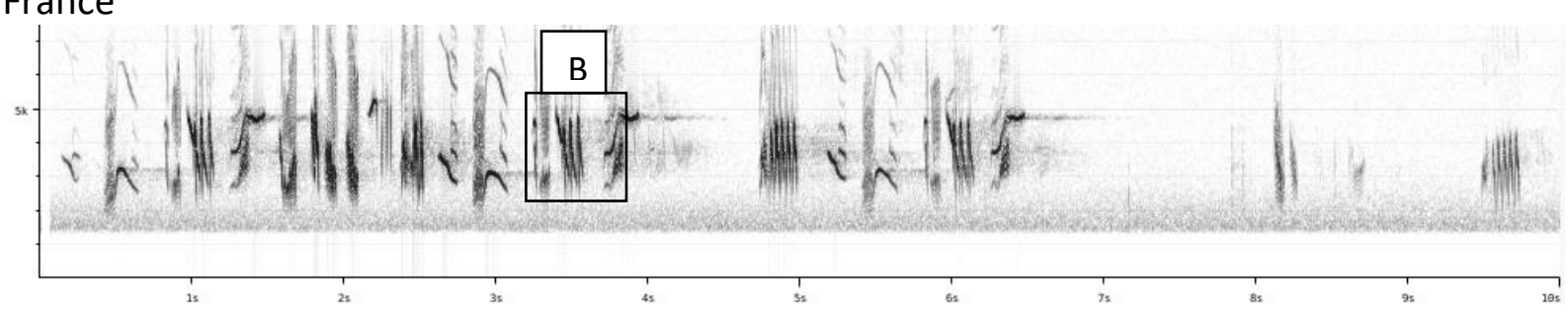

Switzerland

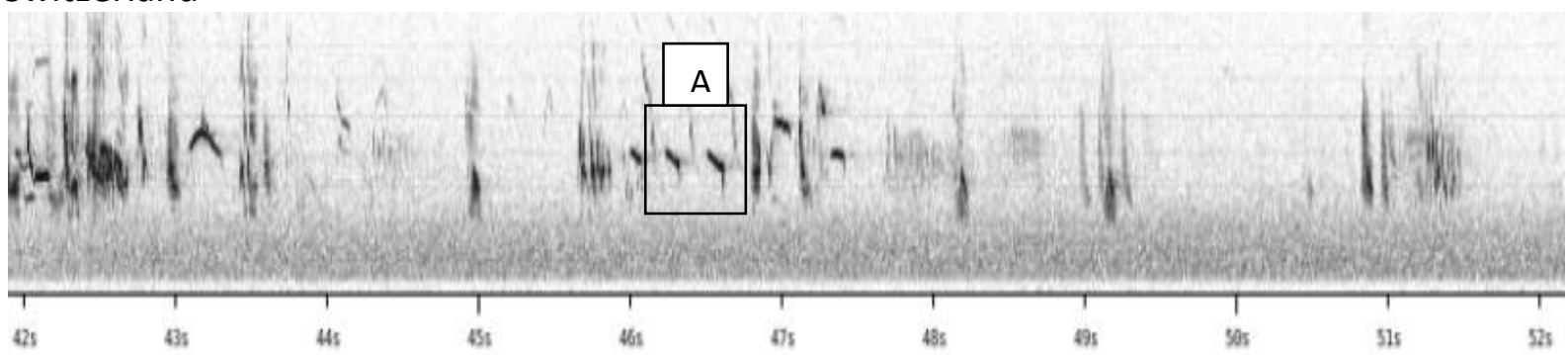




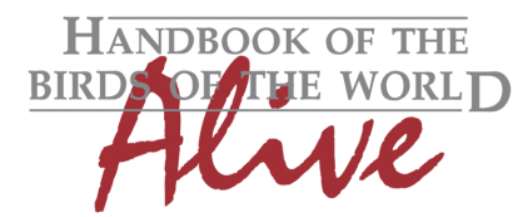

\section{ORNITHOLOGICAL NOTES}

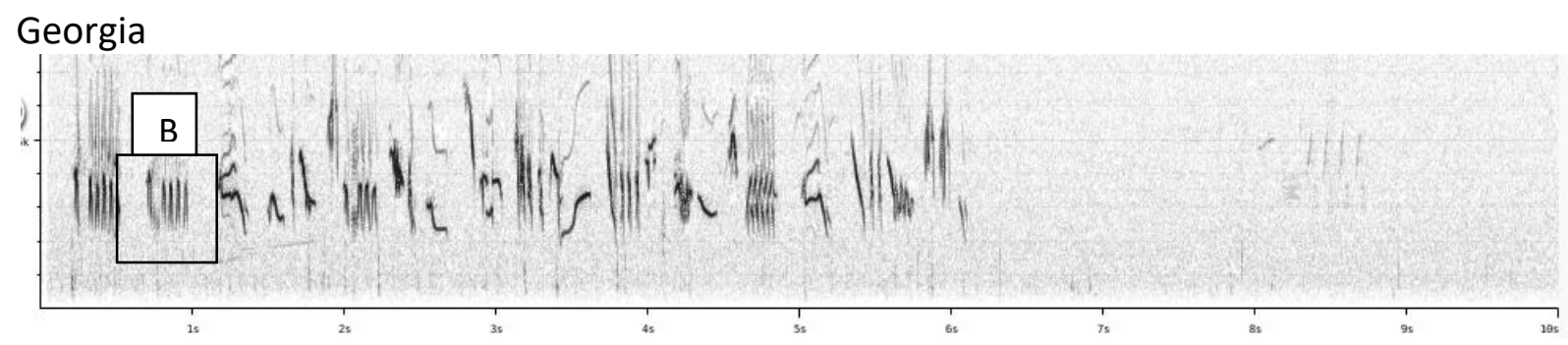

Qinghai, China
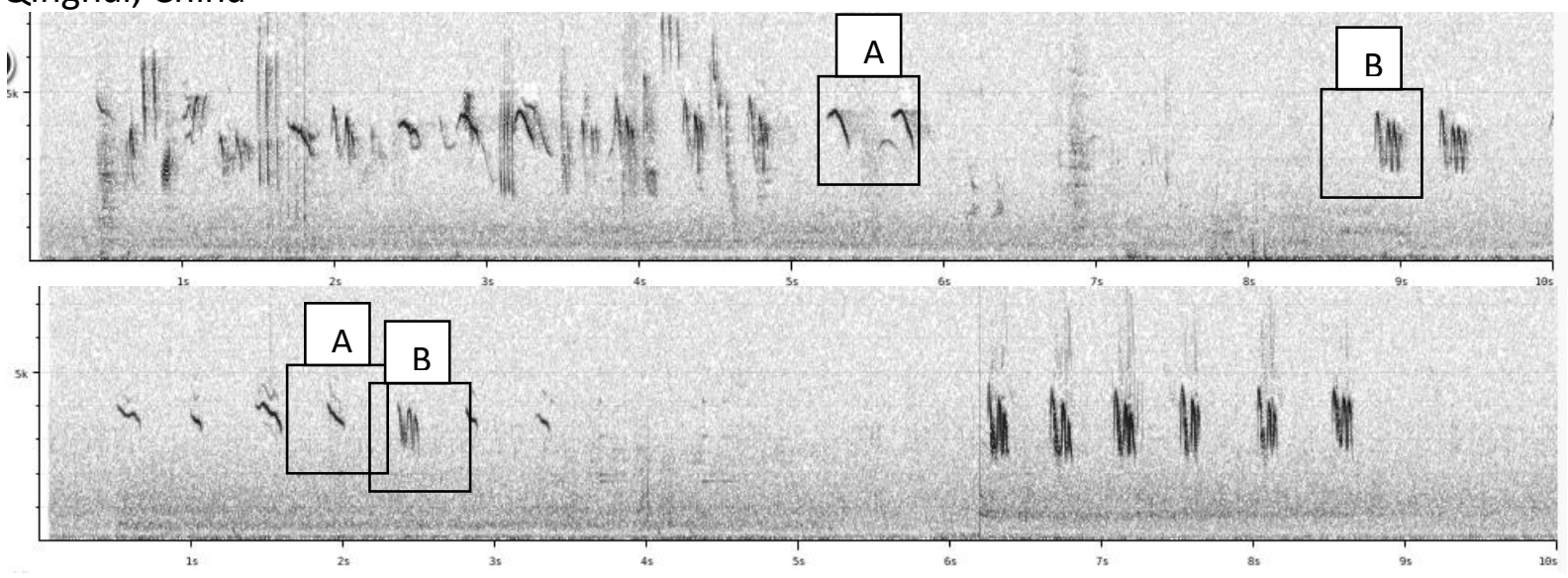

Taiwan

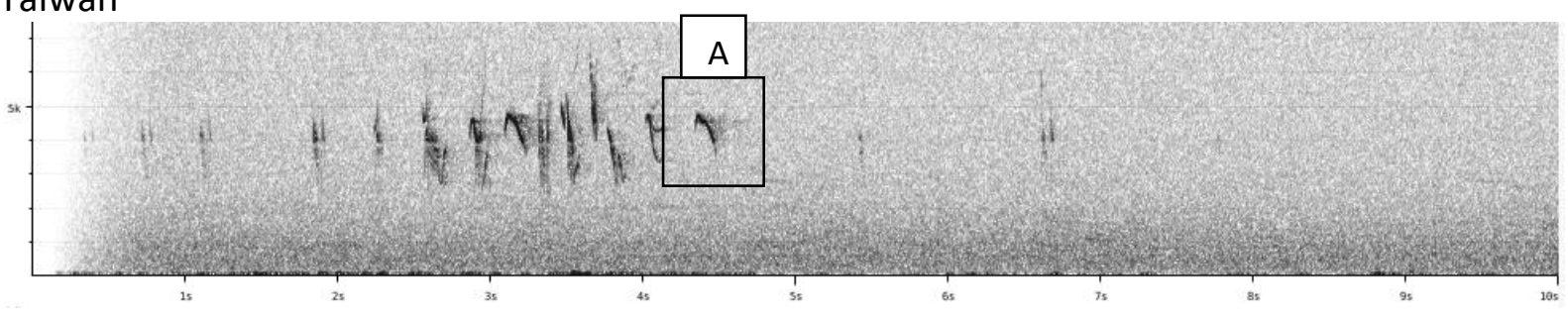

Based on these recordings, it would seem that the note type $A$ is mainly a feature of eastern races (shared with e.g. nipalensis and fennelli) but also found occasionally in western races, while the oscillating note (type B) is a feature of all races (with possibly a gradual change from more and faster oscillations in the west to fewer and slower oscillations in the east).

The fact that in erythropoygia only two note types are used (unlike some much more complex song phrases in other races) may merely be the difference between an early song stage and a 'full song', as illustrated by the two examples above from Qinghai (China).

With just a single recording of erythropygia there is not a lot we can conclude, but it would seem that there are little indications of a truly divergent song.

This note was finalized on 28th April 2016, using sound recordings available on-line at that moment. We would like to thank in particular the sound recordists who placed their recordings for this species on XC: Christian Brinkman, Fernand Deroussen, Marco Dragonetti, Matthias Feuersenger, Chie-Jen Ko, Frank Lambert, Antero Lindholm, Jarek Matusiak, Mike Nelson, Michele Peron, Jelmer Poelstra, Julien Rochefort, Marcin Sotowiej, Lüthi Thomas and John Wright. 


\section{References}

Drovetski, S.V., Semenov, G., Drovetskaya, S.S., Fadeev, I.V., Red'kin, Y.A. and Voelker, G. (2013). Geographic mode of speciation in a mountain specialist avian family endemic to the Palearctic. Ecol. Evol.3(6): 1518-1528. doi: 10.1002/ece3.539

Tobias, J.A., Seddon, N., Spottiswoode, C.N., Pilgrim, J.D., Fishpool, L.D.C. \& Collar, N.J. (2010). Quantitative criteria for species delimitation. Ibis 152(4): 724-746.

\section{Recommended citation}

Boesman, P. (2016). Notes on the vocalizations of Alpine Accentor (Prunella collaris). HBW Alive Ornithological Note 343. In: Handbook of the Birds of the World Alive. Lynx Edicions, Barcelona. (retrieved from http://www.hbw.com/node/1252868 on 26 October 2016). 